Andreas Bergmann

\title{
Die Geschäftsführung ohne Auftrag als Subordinationsverhältnis
}

Die Rechtsinstitute der negotiorum gestio in subordinationsrechtlicher Betrachtungsweise

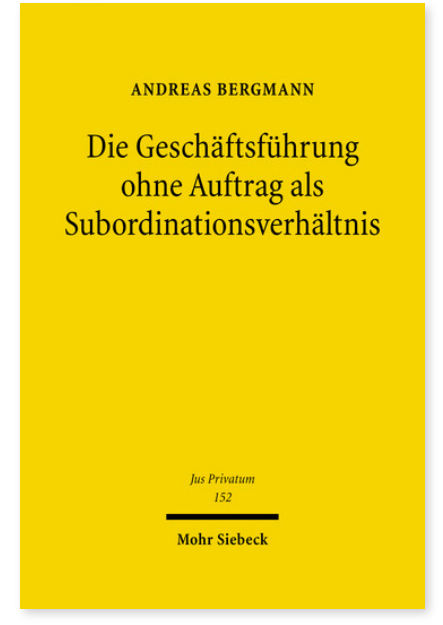

2010. XXII, 505 Seiten. JusPriv 152

ISBN 978-3-16-151229-2

DOI 10.1628/978-3-16-151229-2

eBook PDF $119,00 €$

ISBN 978-3-16-150329-0

Leinen $119,00 €$
Hinter der Überschrift negotiorum gestio (Geschäftsführung ohne Auftrag) verbergen sich drei Rechtsinstitute, die in ihrer Interessenstruktur unterschiedlicher kaum gedacht werden können. Diese strukturelle Dreiteilung des Geschäftsführungsrechts wurde trotz erster Ansätze bei den Glossatoren bisher nicht gesehen. Stattdessen erfolgte im Anschluss an Cujas und Donellus eine Fixierung auf den Begriff des fremden Geschäfts, der die bestehenden Interessenunterschiede nivelliert und unpassende Wertungen in das Recht der GoA implementiert. Folge ist die gegenwärtige Krise des Gestionsrechts, in der zunehmend die Aufgabe der negotiorum gestio als selbständiges Institut gefordert wird. Aus einer subordinationsrechtlichen Betrachtungsweise heraus entwirft Andreas Bergmann ein neues Bild der GoA als selbständiges Rechtsinstitut der nicht durch Gesetz oder Vertrag geregelten, tatsächlich übernommenen Interessenwahrnehmung für einen anderen.

Andreas Bergmann Geboren 1973; 2002 Promotion; 2003 Zweite Juristische Staatsprüfung; 2009 Habilitation; 2010-11 Professor an der Universität Bayreuth; seit 2011 Professor an der Fern-Universtität Hagen, Inhaber des Lehrstuhls für Bürgerliches Recht, Privatrechtsgeschichte sowie Handels- und Gesellschaftsrecht

\author{
Jetzt bestellen: \\ https://mohrsiebeck.com/buch/die-geschaeftsfuehrung-ohne-auftrag-als-subordinationsverhaeltnis-9783161512292? \\ no_cache=1 \\ order@mohrsiebeck.com \\ Telefon: +49 (0)7071-923-17 \\ Telefax: $+49(0) 7071-51104$
}

